\title{
Fundamental Research on the Applications of Clinical Skill Training Centers on the Education of Clinical Medicine
}

\author{
Zhuo Zhang \\ China-Japan Union Hospital, Jilin University, \\ Changchun 130033, Jilin, China \\ Haiyan Zhang* \\ China-Japan Union Hospital, Jilin University, \\ Changchun 130033, Jilin, China \\ Changxia Cheng \\ China-Japan Union Hospital, Jilin University, \\ Changchun 130033, Jilin, China \\ ${ }^{*}$ Corresponding author
}

\begin{abstract}
In this paper, we conduct research on the applications of clinical skill training centers on the education of clinical medicine. To explore effective ways to cultivate the innovative ability of medical students which are the current reform of higher education of clinical medicine and the development is important. Obviously, the change of medical mode of the innovative ability of clinical doctors had the higher request the clinician must have the spirit of doubt and criticism. Our proposed method will enhance the students' ability which will holds special meaning.
\end{abstract}

Keywords: Clinical Skill Training Centers; Clinical Medicine; Education; Fundamental Research.

\section{Introduction}

Along with our country education system from the exam-oriented education to quality education, higher medical education in quality education has been widespread recognition and attention. Along with the development of the change of medical model, medical science and health of the integration of regional planning, higher clinical medical education is facing severe challenges and opportunities for development. Changing teaching idea, renewing education concept, deepen teaching reform, comprehensively promote education innovation, training the new clinical medical talents in the new century, is the basic goal of higher education of clinical medicine. To explore effective ways to cultivate the innovative ability of medical students which are the current reform of higher education of clinical medicine and the development is important. Philosophy and medicine is the relationship between medicine and philosophy commonly interested in a subject, a new generation of medical education must also be under the support of philosophy thought, to break the island of education situation, develop in the global information and knowledge flow under the condition of post competence, to adapt to the trend of internationalization of medical and health undertakings in the new century talented person need. The birth of the new medical model makes medical treatment from a focus on biological into considering comprehensive factors such as society, psychology, biology, from which rely on medical technology and medical department mainly into depending on multidisciplinary cooperation and participation of the whole society and the world big medical, prevention, shift from mainly focused on diseases and health problems to focus on people-oriented and focus on the relationship between human and society and the environment. Obviously, the change of medical mode of the innovative ability of clinical doctors had the higher request the clinician must have the spirit of doubt and criticism, analysis and creation and exploration to study scientific attitude. 
The current problems existing in the education of clinical medicine could be summarized as the follows. (1) Target a single, backward professional caliber too narrow, training mode, and the modern medical mode and medical service mode transform does not adapt. Personnel training mode was largely a product of the biomedical model, the influence of traditional education thought too deep, to adapt to the biomedical and blindly the need of the old health service model, reflected in the trained clinicians with thick still. Pure treatment "characteristics, are used to from the Angle of physics, chemistry and biology to understand the structure and function of human body, analyze the causes of the disease and prevention, medical professional concept has not yet out of heavy light cure against the light, individual light group, medical care and rehabilitation, difficult to adapt to the development of modern medical mode and medical service mode change. (2) Backward education thought and education idea, and the medical science and technology development and the medical students' quality education request does not adapt. For a long time, from the bondage of traditional education ideas and education concept, talents cultivation idea of utilitarianism is strong, talented person quality one-sided. In clinical medical education attaches importance to the teaching of science and technology, ignoring the cultivation of humanistic. Attaches great importance to the professional skills training, ignoring the cultivation of the overall quality and ability and overall harmonious development of medical students, this is clearly with the time requirement for medical talent. (3) Course mode, teaching content and teaching methods, teaching means a single. With the social and economic development requirement about the quality of the medical personnel is not suitable. In quite a long time in the past, due to the shortage of medical services and medicines is very serious, clinical medical education in China has come a quantity to develop, and emphasizes the teaching quality which can be more paid attention only to the number of health personnel training [1].

To deal with the mentioned issues, in this paper, we conduct research on the applications of clinical skill training centers on the education of clinical medicine. Innovative medical talents has four meanings: one is should have the reasonable structure of medical knowledge, that is to say, should not only have solid medical professional basic theory, new scientific knowledge related to the medical profession, and broad knowledge, fork to have skilled medical basic skills and acquire knowledge, have the courage to explore, innovation ability and it is to should have creative thinking, that is, active thinking, good at imagination, positive innovation, follow the scientific laws and is not bound by tradition, search for known areas have a strong interest and desire to create which can from a new perspective on the known field problem, research questions, tries to break through. Three is a strong divergent thinking, and good convergent thinking skills, namely from the existing knowledge and experience, along a different path, get a lot of new and unique ideas, again set into the new structure, so, in order to sublimate. Four is must have the noble quality and indomitable perseverance". In the following sections, we will discuss the issues in detail.

\section{The Proposed Methodology}

The Clinical Skill Training Centers. The composition and function of clinical skill training center establish a fully functional, relatively independent clinical skill training center, including the basic clinical skills training platform, clinical specialist skills training platform, clinical comprehensive skills training platform and clinical skills examination center. Meet the medical students to residency, specialist with different structure, different levels and different stages of teaching, training and examination requirements. To change the status quo of theory teaching and clinical practice is not cohesive, change the abstract book knowledge to 
specific teaching and operation, to make the students more systematic study of clinical knowledge. Due to the constant sound of the medical laws and regulations, the increasing of the medical administration management and the limitation of the rational allocation of medical resources and patients to medical services demand rising, severely impact the traditional clinical teaching methods, the practice of medical students opportunities to decrease year by year. Medical students in the limited practice, practice time full access to the case of need to learn hard. The real value of available teaching resources is reducing year by year. Medical students, because too much rely on lectures, view and can't really get skills related to the clinical the operations, quite a part of the practice teaching activities in the formal, go through the motions. At the same time set up a set of scientific evaluation system, make subjective way of evaluation objective and comprehensive evaluation system. With the improvement of the simulation center, mature course can even by short-term to develop in the direction of degree type education [2].

In general, the clinical skill training centers could be separated into the following parts. (1) Clinical skills training platform. By clinical comprehensive skills of virtual reality simulation system and standardized patients in two parts, mainly through simulated real clinical environment and early clinical patients, let the student contact to improve the comprehensive ability to analyze and solve problems. Standardized patients system is applied to clinical comprehensive skills training which can alleviate patient is hard to find the problem now, and can make the students' comprehensive training feedback sufficiently, objective evaluation. In order to increase the effectiveness of teaching or test, patients can effectively avoid the medical trainee practice teaching of the application of the moral and ethical issues involved in and it can also be used in clinical skills training and assessment. Virtual reality simulation system mainly aimed at the completion of probation teaching, or in the late stage of clinical practice of medical students. (2) Clinical skills examination center. Establish a three-stage clinical examination system, in order to through the various stages of the organic combination of the different examination way, realize the continuous observation of students, objective evaluation the clinical ability and level. (3) Clinical basic skills training platform. Training platform including lab test in the diagnosis of clinical skills teaching, clinical diagnostic skills teaching laboratory, digital imaging based teaching laboratory teaching laboratory and proc. Pay attention to the doctor-patient communication and diagnostic skills. With the help of heart and lung auscultation, abdominal palpation model and so on to strengthen the teaching of physical examination skills. Optimization experiment diagnostics experiment project, emphasize the students should master the experimental diagnosis of concept, the principle of universality and practicality. In terms of imaging diagnostic skills teaching, explore using digital teaching platform, integrating practice base for many images of electronic resources, medical imaging, multimedia teaching; Based on surgical operative surgery teaching, try to simulate the real operation environment and the request, let the student to adapt as soon as possible, and to form a good habit of aseptic operation. (4) Clinical specialist skills training platform. Using advanced integrated model of clinical medical students must master the simulated training of various professional skills, lets the student during the undergraduate study at the university is to master the clinical students should master professional skills and to eventually emphasize the standardization of diagnosis and treatment technology [3].

The Education of Clinical Medicine. Medical education is a practical very strong science. The medical students from entering school to graduate only completed the introduction to medical education. And during 
the period of school learning can be divided into three stages, namely basic course education, clinical medical professional knowledge education and graduation practice. With professional knowledge education stage is the key to the medical students in clinical practice period, students at this stage should not only learn the academic knowledge on book, more important is to see the real patients. As the total number of medical colleges and universities increased enrollment students continue to increase, and the teaching hospital in the medical market competition and under the influence of medical insurance policy, bed utilization rate, reduce the sick, the disease is not complete. In addition because the ego to protect consciousness of patients has been increasing and refused to the student body and does all kinds of medical operation, all of this leads to the trainee in clinical medical education and practice the difficulty increases, unable to complete the teaching plan to see to do project. Education of thoughts and ideas change was the forerunner of innovation education, the teaching reform to a breakthrough, the first thing to break the bondage of traditional education thought. With the rapid development of social economy, politics, culture, science and technology with each passing day, knowledge update speed and the contradiction between limited teaching time, give priority to with knowledge of clinical medical education cannot meet the needs of the development of society, followed by the lifelong education of clinical medicine.

Clinical medical education, therefore, in addition to teach students the basic medical knowledge, skills, more important is to train and cultivate their innovative learning methods and thinking mode, form the good habit of lifelong learning. In most medical students in clinical practice, teaching management and clinical teachers' imparting more focus on clinical knowledge and basic operation training, and the lack of clinical training and cultivate creative thinking of students. Some interns have few operations training opportunity, at the end of the internship, can't even basic clinical operation, let alone the cultivation of innovation ability. Practice examination is the main test theory, operation, some given scores by heart and therefore, we must first clear the purpose of internship is to develop qualified medical talents with plane new thinking and ability, practice task is to teach basic theoretical clinical and basic clinical skills training, training medical innovative thinking and ability, shape noble medical ethics quality. Pay special attention to the construction of clinical teaching. Implementation of innovative talent training system, the practice of innovative education mode of clinical medicine in the end to put on the teacher, to establish to the cultivation of innovative talents innovation of teachers' team is particularly important. Higher medical colleges and universities should organize teachers learning the connotation of innovation education, thoughts and ideas, by increasing of laboratories, library, information engineering, scientific research fund input, such as for teachers to create favorable conditions and atmosphere of innovation education, and teachers' education, training, let the teacher learning innovation education method, using various incentives which will arouse the enthusiasm of the innovation of teacher education.

The Prospect and Suggestions. Clinical medicine is a practical discipline, its research object is a person, is directly related to human life and health. Clinical practice teaching is an important guarantee of teaching quality of clinical medicine. With the development of modern society and medical education technology, all kinds of new training simulation equipment, equipment emerge in endlessly, means and methods of clinical practice teaching will be change essentially. Medical vivid hand ability has been the important and difficult in the process of teaching, if only by the hospital and hospital affiliated to exercise the student's beginning ability is obviously far cannot satisfy 
the requirement of students training objectives, clinical skill training center of colleges and universities is the practice of medical students' practical hands-on opportunities and set up perfect training base. For undergraduate medical education, clinical skill center is basic clinical skills of medical students learning platform, is a bridge that crosses from the essential basic medicine and clinical medicine, can improve the quality of clinical teaching, cultivate students' clinical thinking ability, center of clinical skills in modern medical education plays an irreplaceable role. School of medicine, clinical skill training center is designed to make students to master some necessary before entering clinical practice skills, in order to improve the clinical teaching quality, cultivate the students' clinical thinking ability.

School of medicine, clinical skill training center is designed to make students to master some necessary before entering clinical practice skills, in order to improve the clinical teaching quality, cultivate the students' clinical thinking ability. With all kinds of new training simulation equipment, not for rapid development of medical means and methods of clinical skill training will be change essentially. Clinical simulation situation set it, prompting early exposure to clinical students, at the same time all sorts of model, simulated teaching equipment for medical students to create the practice opportunity, its intuitive, clear, town warbler after many times, shows the superiority of teaching. We firmly believe that through the proposed method, students' ability will be enhanced.

\section{Conclusion}

In this paper, we conduct research on the applications of clinical skill training centers on the education of clinical medicine. Simulation teaching is one of the hot spot of the current medical education reform which is the inevitable trend of medical education development. By creating various clinical scenarios, and provides the health professional and technical personnel at various levels and of clinical skills training, to the cultivation of professional and technical personnel clinical basic ability is of great significance. Therefore clinical skills training is to cultivate all kinds of health technical personnel at all levels of clinical ability is the most important teaching link, and the clinical practice teaching is an important guarantee of the quality of medical education.

\section{References}

[1] Jiang D X, Ning B, Wei L I, et al. Present Situation Analysis of the Primary Hospital Young Doctors Clinical Quality and the Training Countermeasures[J]. Medicine \& Philosophy, 2014.

[2] Luo, P. (2014). Observation on the control effect of parents' intensive training on children with repeated respiratory tract infection. Clinical Medicine \& Engineering.

[3] Ploughman M, Austin M W, Glynn L, et al. The Effects of Poststroke Aerobic Exercise on Neuroplasticity: A Systematic Review of Animal and Clinical Studies[J]. Translational Stroke. 